\title{
Formation, Accumulation and Development of Human Capital in the Modern Conditions
}

\author{
Submitted 03/02/19, $1^{\text {st }}$ revision 07/03/19, accepted 18/04/19
}

\author{
S.V. Titova ${ }^{1}$, Yu.N. Surikov ${ }^{2}$, O.Yu. Voronkova ${ }^{3}$, \\ T.V. Skoblikova ${ }^{4}$, I.V. Safonova ${ }^{5}$, R.A. Shichiyakh ${ }^{6}$
}

\begin{abstract}
:
Purpose: The aim of the study is to identify trends in the formation of human capital. Design/Methodology/Approach: The theoretical and methodological basis of the research is the scientific works of domestic and foreign scientists in the field of labor economics, human capital and management. Historical, statistical, economic and social sources of information were used to approach the subject under modern conditions.

Findings: It was revealed that in the rural and urban areas the reproduction of human resources is carried out at various rates. The demographic factors influencing the reproduction of labor resources in the Russian Federation were analyzed.

Practical implications: The authors substantiated the conclusions that the existence of problems in the development of rural territories is the result of the insufficient effectiveness of the measures taken by state authorities in the agrarian sphere.

Originality/Value: Recommendations were made to improve the efficiency of social and economic policy in rural areas, including an increase in government subsidies to social infrastructure facilities, including feldsher-obstetric items, objects of pre-school and school education and culture.
\end{abstract}

Keywords: Human Capital, Morality, Reproduction, Cultural Values, Rural Areas.

JEL Classification: Q18, O15, O31.

Paper type: Research article.

\footnotetext{
${ }^{1}$ Kazan Innovative University named after V.G. Timiryasov (IEML), Kazan, Russia

${ }^{2}$ Northern (Arctic) Federal University named after M.V. Lomonosov, Arkhangelsk, Russia

${ }^{3}$ Altai state University, Barnaul, Russia. E-mail: olka2004@yandex.ru

${ }^{4}$ Southwest State University, Kursk, Russia

${ }^{5}$ Financial University under the Government of the Russian Federation, Moscow, Russia

${ }^{6}$ Kuban State Agrarian University named after I.T. Trubilin, Krasnodar, Russia
} 


\section{Introduction}

The formation of the quantitative component of the labor resources of the Novosibirsk region clearly reflects the socio-economic, demographic and geopolitical features of rural development in the entire state and at the same time has its own specifics due to the economic attractiveness of the region from the less developed municipal districts of the country.

Under current conditions, the development of market relations requires more improved approaches to the resource supply of the agricultural sector, through the creation of a new mechanism for the reproduction of human capital. This mechanism should include a more effective system of socio-economic relations in rural areas. The current mechanism for the reproduction of human capital shows its inconsistency, which is vividly illustrated in this study. The lack of skilled workers leads to increased wear of agricultural equipment and a decrease in soil fertility, which is extremely negative for economic performance indicators of the agricultural sector (Rudoy et al., 2016).

\section{Literature Review}

In modern conditions, issues of reproduction and use of human capital tend to increase. This is because the development of science and technology requires employees to constantly improve their skills and readiness for continuous training and retraining. Turning to the origins of the theory of human capital, I would like to emphasize that the first references to human capital are found in the writings of Plato and Aristotle. Plato wrote that “... proper upbringing and training awakens good natural inclinations in a person, and from whom they already were, thanks to such upbringing they become even better - in general, and in the sense of transferring them to their offspring, which is observed in all living creatures" (Plato, 1998). Aristotle pointed out that "virtue is of two kinds - mental and moral"; and if moral is born by habit, then "mental arises and increases mainly due to learning" (Aristotle, 2002).

The thoughts of the eminent philosophers of the ancient period lay at the origin of the theory of human capital. This theory has undergone a long evolution and as a scientific concept formed in the middle of the twentieth century. Thanks to outstanding scientists - Theodor Schulz and Gary Bekker. T. Schulz called human capital "a form of capital that serves as a source of future earnings or future satisfaction, or both. And he becomes human because he is a component part of man." According to T. Schulz, the accumulation of a person's ability to work, the preservation of health, spiritual development is the main result of investments in a person. He proved that human capital could accumulate and reproduce (Schulz, 1960). It is worth noting that in modern conditions human capital is the basis for increasing the economic growth of the state. President of the Russian Federation V.V. During the message to the Federal Assembly, Putin pointed out that "The 
meaning of our entire policy is to save people, to increase human capital as the main wealth of Russia. Therefore, our efforts are aimed at supporting traditional values and families, at demographic programs, at improving the ecology, people's health, at developing education and culture" (Putin, 2016).

\section{Methodology}

The theoretical and methodological basis of the research is the scientific works of domestic and foreign scientists in the field of labor economics, human capital management, regulatory and legal acts of the Russian Federation, materials and recommendations of scientific and practical conferences. Scientific methods were used: historical, statistical and economic, monographic.

\section{Results}

Turning to the assessment of the formed human capital of the Novosibirsk region, we would like to point out that the region ranks third in number after the Central and Volga districts. Possession of the largest logistics complex in the region, including the presence of a river port, railways and highways, as well as the TransSiberian Railway, makes the region attractive not only from an economic point of view, but also from the point of view of realizing the internal potential of the region's residents. A very significant is the economic potential, which is predetermined using knowledge-intensive industries (Andronov et al., 2016), as well as the use of intensive factors of production, ensuring high technology development. Socio-economic development is based not only on the level of productive capabilities, but also on those who live in the region. The population is the main productive force of the Novosibirsk region. The Novosibirsk Region is a region with a highly developed agricultural sector (Nikiforov et al., 2019). Because the region has a sharp continental climate, livestock breeding prevails in the southwestern and western parts, and plant growing prevails in the central and southeastern parts.

It should be noted that the region accounts for $25 \%$ of all agricultural land in the Siberian Federal District. Climatic conditions of the region have a positive effect on the cultivation of grain crops, vegetables and potatoes. The most important livestock industry is meat and dairy cattle breeding and poultry farming. The accelerated development of the agricultural sector and the high return on investment have a positive effect on the development of other economic sectors. Technological renewal of the industry, accompanied by the transition to energysaving and resource-saving technologies (Dashko and Lebedeva, 2017), which involves the use of innovative technologies, as well as compliance with technological regulations in preparing animal feed, feeding, milking, using the latest equipment, as well as automating many processes (Nikulin and Romanov, 2017; Kuznetsova et al., 2017). The fulfillment of these tasks is possible only with 
the use of skilled labor capable of working with industry-specific technological regulations that can ensure regulatory recoupment of costs. The efficiency of agriculture largely depends on the supply of workers with a completely new economic thinking, professionalism, knowledge of the foundations of jurisprudence, a certain level of culture, and motivation for the final economic result. (Shelkovnikov et al., 2016).

In view of the above, we would like to note that the formation and development of human capital in the industry is an important condition for the successful development of agriculture in the Novosibirsk region. The increase in labor productivity, due to the use of the latest technologies, assumes completely new approaches to the formation of human capital. An important role is played by the prediction of the basic parameters of the reproduction of human capital, which has recently been considered by many research economists as the main factor in the development of economic relations. In 2018, the population of the Novosibirsk region amounted to 2788.8 thousand people, which is 9.3 thousand people more than the value of the previous year. The population density is 15 people. per $1 \mathrm{~km}^{2}$ (Figure 1).

Figure 1. Dynamics of the number of populations of the Novosibirsk Region, people

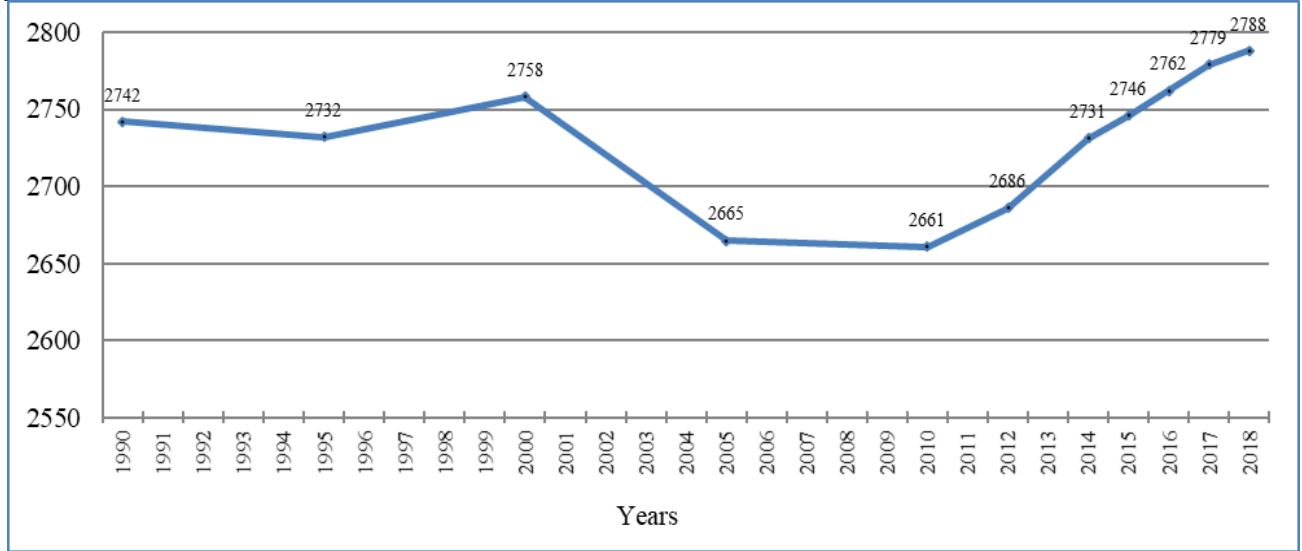

It should be noted that the main part of the region lives in urban areas - 2204.3 thousand people $(79 \%)$. Over the past year, the number of urban residents increased by 10.6 thousand people, or by $0.5 \%$. Despite the increase in the number of people living in the region, the proportion of the population living in rural areas decreased by 17.5 thousand people, or $2.9 \%$. On average, the annual increase in the number of the Novosibirsk region increases by 20 thousand people (Table 1) (Shelkovnikov et al., 2018). On the existing problems in the agricultural industry, according to E.V. Rudoy and other authors show a stable migration outflow of the rural population, observed since the beginning of economic reforms in the state. 
Table 1. The main demographic indicators of the Novosibirsk region, thousand people

\begin{tabular}{|c|c|c|c|c|c|c|c|}
\hline \multirow[t]{2}{*}{ Population } & \multicolumn{7}{|l|}{ Years } \\
\hline & 1997 & 2013 & 2014 & 2015 & 2016 & 2017 & 2018 \\
\hline Total & 2724,0 & 2709,5 & 2731,2 & 2746,2 & 2762,2 & 2779,6 & 2788,8 \\
\hline \multicolumn{8}{|l|}{ Including: } \\
\hline $\begin{array}{l}\text { Urban } \\
\text { population }\end{array}$ & 2013,0 & 2110,0 & 2135,9 & 2156,8 & 2179,9 & 2193,8 & 2204,3 \\
\hline $\begin{array}{l}\text { Rural } \\
\text { population }\end{array}$ & 710,96 & 599,5 & 595,3 & 590,0 & 587,4 & 585,8 & 584,5 \\
\hline \multicolumn{8}{|c|}{ Share in total population, $\%$} \\
\hline $\begin{array}{l}\text { Urban } \\
\text { population }\end{array}$ & 73,9 & 77,9 & 78,2 & 78,5 & 78,9 & 78,9 & 79,1 \\
\hline $\begin{array}{l}\text { Rural } \\
\text { population }\end{array}$ & 26,1 & 22,1 & 21,8 & 21,5 & 21,1 & 21,1 & 20,9 \\
\hline
\end{tabular}

Long-term monitoring of state statistics bodies of quantitative indicators of human capital in difficult climatic conditions shows that by 2036 the proportion of people living in rural areas of the region will not exceed 15\% (Figure 2) (Rudoy et al., 2016).

Figure 2. The predicted values of the urban and rural population in the Novosibirsk region

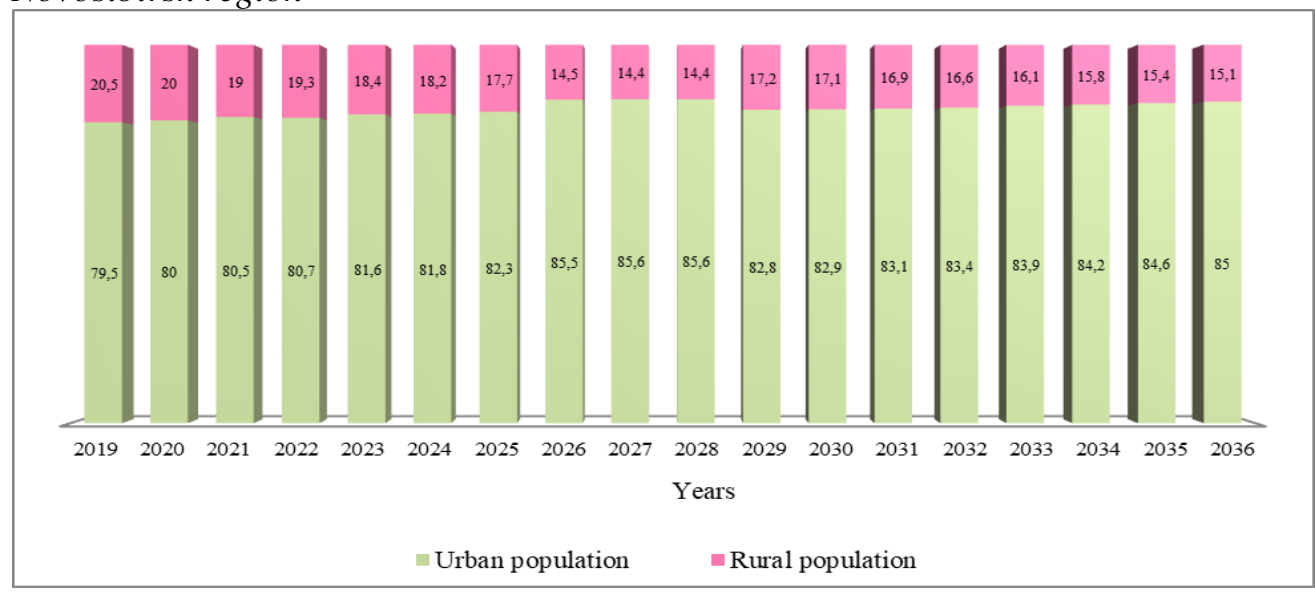

For 2017, the birth rate per 1000 population tends to decrease. In urban areas, it is 12.4 people per 1000 population, for the year it has decreased by $10 \%$. The fertility rate in urban ar-eas for several years significantly exceeds the birth rate of the rural population. In rural areas, the depopulation process continues; excess of mortality over birth rate. According to E. Rudoy soon, in order to preserve the natural growth of the population, government agen-cies need to take certain measures in this direction (Table 2) (Rudoy et al., 2015). 
Table 2. Demographic indicators of the rural area of Novosibirsk region

\begin{tabular}{|l|l|l|l|l|l|l|l|l|l|}
\hline Year & Born & Dead & $\begin{array}{l}\text { Natural increase } \\
\text { (decrease) }\end{array}$ & $\begin{array}{l}\text { The number of } \\
\text { children who died } \\
\text { at the age of 1 year }\end{array}$ \\
\cline { 2 - 10 } & Total & $\begin{array}{l}\text { Per 1000 } \\
\text { population }\end{array}$ & Total & $\begin{array}{l}\text { Per 1000 } \\
\text { population }\end{array}$ & Total & $\begin{array}{l}\text { Per 1000 } \\
\text { population }\end{array}$ & Total & $\begin{array}{l}\text { Per 1000 } \\
\text { population }\end{array}$ \\
\hline Urban population \\
\hline 2013 & 29127 & 13,4 & 26995 & 12,7 & 2132 & 1,0 & 195 & 6,7 \\
\hline 2014 & 29335 & 13,7 & 27127 & 12,6 & 2207 & 1,1 & 185 & 6,3 \\
\hline 2015 & 31369 & 14,5 & 26755 & 12,4 & 4614 & 2,1 & 178 & 5,7 \\
\hline 2016 & 30541 & 14,0 & 27140 & 12,4 & 3401 & 1,6 & 177 & 5,8 \\
\hline 2017 & 27346 & 12,4 & 26946 & 12,3 & 400 & 0,1 & 125 & 4,5 \\
\hline Rural population \\
\hline 2013 & 9168 & 15,3 & 9576 & 16,0 & -408 & $-0,7$ & 67 & 7,3 \\
\hline 2014 & 9052 & 15,3 & 9228 & 15,6 & -176 & $-0,3$ & 77 & 8,5 \\
\hline 2015 & 7709 & 13,1 & 9273 & 15,8 & -1564 & $-2,7$ & 56 & 7,1 \\
\hline 2016 & 7644 & 13,0 & 9011 & 15,4 & -1367 & $-2,4$ & 62 & 8,1 \\
\hline 2017 & 7102 & 12,1 & 8884 & 15,2 & -1782 & $-3,1$ & 48 & 6,7 \\
\hline
\end{tabular}

As can be seen from the table, the natural decline in the population in rural areas is becoming more and more aggravated every year, and in 2017 , the mortality rate is far ahead of the birth rate per 1000 population. If we look at the dynamics, then in 2017,3847 or $10 \%$ of children were born less than in 2013 . The total fertility rate in rural and urban areas is almost equal and amounts to $12.4 \%$ per 1000 inhabitants. As for the general mortality rate, it is much higher in rural settlements, which has an extremely adverse effect on the formation of human capital in rural areas. In order to achieve an improvement in the demographic situation in the long term, it is necessary that the total fertility rate, that is, the number of children born per woman is at least 2.15 (Table 3).

Table 3. The Number of rural populations of the Novosibirsk region

\begin{tabular}{|l|l|l|l|l|l|l|}
\hline Years & $\begin{array}{l}\text { Population } \\
\text { at the } \\
\text { beginning } \\
\text { of the year, } \\
\text { people }\end{array}$ & $\begin{array}{l}\text { Changes for the year } \\
\text { increase }\end{array}$ & $\begin{array}{l}\text { Migration } \\
\text { gain }\end{array}$ & $\begin{array}{l}\text { Overall } \\
\text { gain }\end{array}$ & $\begin{array}{l}\text { Population } \\
\text { at the end } \\
\text { of the year, } \\
\text { people }\end{array}$ & $\begin{array}{l}\text { Total } \\
\text { growth } \\
\text { for the } \\
\text { year, \% }\end{array}$ \\
\hline 1990 & 702123 & 2473 & -6730 & -4257 & 697866 & $-0,61$ \\
\hline 2011 & 605045 & -799 & -1604 & -2403 & 602642 & $-0,41$ \\
\hline 2012 & 602642 & -317 & -2855 & -3172 & 599470 & $-0,53$ \\
\hline 2013 & 599470 & -408 & -3732 & -4140 & 595330 & $-0,69$ \\
\hline 2014 & 595330 & -176 & -5150 & -5326 & 590004 & $-0,89$ \\
\hline 2015 & 590004 & -1564 & -1071 & -2635 & 587369 & $-0,45$ \\
\hline 2016 & 587369 & -1367 & -214 & -1581 & 585788 & $-0,27$ \\
\hline
\end{tabular}

The increase in the birth rate for 2012-2017. was due to the onset of the childbearing age of children born in the $80 \mathrm{~s}$, including an increase in the number of female populations. However, in the next few years, the number of females between the ages of 20 and 30 will decrease, which is a negative consequence of 
the demographic crisis of the early 1990s years. In view of the above, it can be concluded that soon depopulation will repeat to a greater degree, and this will have an extremely negative impact on the formation of human capital. Since the main component of depopulation is low birth rate, the main guideline for improving the demographic situation should be a family with at least 3 children. A large role in shaping the social image of a person is played by the mass media. Creating patterns of behavior that can increase the moral decay of society leads to the need to foster in young people a responsible attitude towards the continuation of the race, motherhood and fatherhood in the future. Negative images that are widely spread on television have a very detrimental effect on a person's life, threatening the national security of the state.

The words of the Vice-President of the Hudson Institute, Enders Wimbush, were somewhat prophetic. He once said: "There is no turning back, it is unlikely that Russia will be saved or save itself from such depletion of human capital that will make it inconvenient or even unviable." In his opinion, Russia in its present form may cease to exist in the future. Strong family relationships, stability, monogamy and the duration of marital relations are the key to healthy offspring and the foundation of sustainable economic development. Thus, the opinion of many researchers that the main reason for depopulation is the low standard of living is not always justified. Today, the decline in the birth rate is caused not only by economic factors that adversely affect the formation of human capital, but also by a decrease in the level of morality and spirituality of the population (Kuznetsova et al., 2018).

\section{Conclusion}

A long period of reforms taking place in the Russian economy led to radical and irreversible changes in the lives of the rural population. Most researchers agree that the Russian village is experiencing a deep demographic crisis in today's conditions that has a very negative impact on the efficiency of agriculture. The authors in this study substantiated the conclusions that in rural areas there is an acute demographic problem, which is a consequence of the lack of effectiveness of state programs implemented in recent years in the agrarian sector. In view of the above, it follows that the problems of reproduction of human capital affect the competitiveness of agricultural production and the massive release of labor resources from the sphere of agricultural production.

Thus, it can be concluded that the issue of solving the demographic problem in rural areas is highly relevant and requires immediate action by public authorities. It is important to note that the observed negative trends in the formation of human capital in the rural areas of the Novosibirsk region can only be overcome if the quality of life in the villages meets the requirements arising from the specifics of the entire region. We should not forget that the development of rural territories is a 
strategic interest of the state, since the solution of the problem of ensuring the national food security of the Russian Federation depends on their development. Thus, the control over the reproduction of labor resources in rural areas requires increased attention and significant government injections, primarily in social infrastructure facilities.

\section{References:}

Aristotle. 2002. Ethics. Moscow: AST, p. 492.

Andronov, G.P., Zakharova, I.B., Filimonova, N.M., L’vov, V.V. \& Aleksandrova, T.N. 2016. Magnetic separation of eudialyte ore under pulp pulsation. Journal of Mining Science, 52(6), 1190-1194, doi:10.1134/S1062739116061735.

Dashko, R.E., Lebedeva, Y.A. 2017. Improving Approaches to Estimating Hydrogeological Investigations as a Part of Engineering Survey in Megacities: Case Study of St. Petersburg Water Resources, 44(7), 875-885. DOI: 10.1134/S009780781707003X.

Kuznetsova, I., Voronkova, O., Bakvalov, S., Ruiga, I., Zhuruli, G., Levichev, V. 2018. Formation of Human Capital as a Key Factor in Ensuring the National Security of Agriculture in the Digital Economy. European Research Studies Journal, Volume XXI, Special Issue 3, 73-83.

Kuznetsova, A.N., Gunkin, A.S. \& Rogachev, M.K. 2017. Dynamic modeling of surfactant flooding in low permeable argillaceous reservoirs. Paper presented at the IOP Conference Series: Earth and Environmental Science, 87(5), doi:10.1088/1755$1315 / 87 / 5 / 052014$.

Nikulin, A. \& Romanov, A. 2017. Control over the use of personal protective equipment by employees, head protection. Ecology, Environment and Conservation, 23(1), 384389.

Nikiforov, A.V., Vinogradov, E.A. \& Kochneva, A.A. 2019. Analysis of multiple seam stability. International Journal of Civil Engineering and Technology, 10(2), 11321139.

Plato. 1998. State. Laws. Politician. Moscow: Thought, p. 798.

Putin, V. 2016. Annual Message of the President to the Federal Assembly of 12/11/2016. Rossiyskaya Gazeta, №51, (39), 13.

Rudoy, E.V., Shelkovnikov, S.A., Matveev, D.M., Sycheva, I.N., Glotko, A.V. 2015. Green box and innovative of agriculture in the Altai territory of Russia. Journal of Advanced Research in Law and Economics, Vol. 6, № 3, 632-639.

Rudoy, E.V., Stasiulis, M.V., Samokhvalova, A.A., Vyshegurov, M.S., Iakimova, L.A. 2016. Development of agrofood market in the southern part of siberia by means of regional and food relations. International Journal of Applied Business and Economic Research, Vol. 14, № 9, 5875-5890.

Shelkovnikov, S.A., Kuznetsova, I.G., Poddueva, I.S., Hodos, D.V., Yakimova, L.A., Ganieva I.A. 2016. Regulation of the labor market and human capital in the agrulture of the Novosibirsk region. International Journal of Economic Research, № 9, Vol. 13, 3829-3845.

Shelkovnikov, S.A., Kuznetsova, I.G., Denisov, D.A., Peshkova, O.O., Malyshev, Y.A. 2018. Enhancing the instruments of state support for the process of building human capital. International Journal of Civil Engineering and Technology (IJCIET) Volume 9, Issue 8, 1633-1641.

Schulz, T. 1960. Capital Formation bi Edukation. Journal of Politikal Economu, p. 216. 